\title{
LA GESTIÓN DEL PATRIMONIO ARQUEOLÓGICO EN EL ANTIGUO PROTECTORADO ESPAÑOL EN EL NORTE DE MARRUECOS. GESTIÓN, ADMINISTRACIÓN, NORMATIVAS
}

\author{
THE MANAGEMENT OF THE ARCHAEOLOGICAL HERITAGE IN THE FORMER SPANISH \\ PROTECTORATE IN THE NORTH OF MOROCCO. MANAGEMENT, ADMINISTRATION, POLICY
}

\author{
JAVIER VERDUGO SANTOS* \\ MANUEL J. PARODI ÁLVAREZ**
}

\begin{abstract}
Resumen: Una de las tareas esenciales en la gestión del Patrimonio Arqueológico del Norte de Marruecos a lo largo de la primera mitad del siglo XX sería el establecimiento de estructuras organizativas y legales que viniesen a crear una auténtica administración destinada a la gestión del referido $\mathrm{Pa}$ trimonio. Tras la inestabilidad del territorio en las primeras décadas del siglo, avatares como la Guerra Civil española o la propia II Guerra Mundial vendrían a dificultar aún más este proceso. Finalmente, la acción de la administración hispano-marroquí, impulsada por determinadas figuras singulares, vendría a dar forma a una estructura real que velaría por la gestión patrimonial a lo largo de varias décadas y los resultados de cuyo trabajo se hacen notar aún hoy.

Palabras clave: Norte de Marruecos, España, Patrimonio Arqueológico, Monumentos, Ley, Protectorado.
\end{abstract}

\section{NATURALEZA JURÍDICA DEL TERRITORIO MARROQUÍ SOMETIDO AL PROTECTORADO ESPAÑOL}

Por Protectorado debemos entender una "unión" de Estados en relación de desigualdad. De acuerdo

\footnotetext{
* Arqueólogo Conservador de Patrimonio. Jefe de Servicio de Planificación y Evaluación de los Bienes Culturales, Dirección General de Bienes Culturales, Consejería de Cultura, Junta de Andalucía.

** Historiador. Grupo de Investigación PAI HUM 402 "Historiografía y Patrimonio de Andalucía” (Universidad de Sevilla).
}

Abstract: The main task regarding the Archaeological Heritage in Northern Morocco during the first half of the $\mathrm{XX}^{\text {th }}$ Century was to establish the necessary legal and functional structures in order to create a real administration devoted to manage that Archaeological Heritage. After the tough and conflictive two first decades of the Century, other main historical matters as the Spanish Civil War or World War Two added more difficulties to this complex process. Finally, the active action of the Spanish-Morocco administration, as well as the work of several individuals, got through every trouble succeeding in creating a real structure to care and protect the Heritage, which stayed alive for several decades and which action has served as a basis for the current structures.

Key words: Northern Morocco, Spain, Archaeological Heritage, Monuments, Law, Protectorate.

con Ch. Rousseau (1966: 143-150) tres son los caracteres de un territorio sometido a protectorado. En primer lugar se trata de un régimen establecido entre dos Estados: el protector y el protegido. Segundo, dicho régimen es convencional, ya que siempre se constituye por medio de un tratado. Y en tercer lugar, el protectorado implica una distribución de competencias entre ambos Estados, más sensible en el orden interno que en el internacional. Precisamente esta última característica confiere una especial naturaleza al derecho interno, que podemos concretar en la existencia de tres competencias esenciales en la relación 
entre los dos Estados. Así, y en lo que respecta a la competencia territorial, la naturaleza jurídica del territorio del Estado protegido ha sido asimilada, unas veces, al territorio del Estado protector, otras a la consideración de territorio extranjero y por último, también se ha considerado, unas veces, territorio del Estado protegido y otras del Estado protector. La opinión más común es la de considerar el territorio sometido a protectorado como parte integrante del Estado protegido, en el que el Estado protector ejerce unas competencias regladas. En cuanto a la competencia personal, que es la que se ejerce sobre las personas que habitan el protectorado, ésta implica que los habitantes no son nacionales del Estado protector, sino que son protegidos o ressortissants, es decir dependientes de una jurisdicción o bajo su dependencia y se benefician de la protección diplomática. Por último, el Estado protector asume la competencia de los servicios públicos que se materializa mediante la presencia de tropas, administración civil y sistema judicial. Finalmente, y en lo concerniente a la política exterior el Estado protector ejerce el monopolio de las competencias, siendo todas las relaciones diplomáticas con terceros sometidas a la intermediación del Estado protector.

Sobre estas premisas debemos acometer el análisis de la naturaleza jurídica de los territorios sometidos a protectorado por el Estado Español en Marruecos. En el caso que nos ocupa el sistema del protectorado español se basaba en el respeto de la personalidad jurídica internacional de Marruecos y el territorio protegido seguía perteneciendo a Marruecos. El régimen administrativo reflejaba el dualismo de la naturaleza jurídica del protectorado: dos Estados, dos administraciones. Una marroquí a cuyo frente se encontraba el Jalifa que ejercía sus competencias por mandato del sultán, y en especial la facultad legislativa, por medio de decretos (dahir). Circunstancia que nos permite asignar a las autoridades españolas la acción ejecutiva o de gobierno a través de la gestión de los servicios públicos. Sin embargo el Jalifa disponía de un aparato administrativo importante denominado el Majzen, que poseía varios departamentos coordinados por un Visir. Los ministros eran el qadi al-audat (justicia), el Visir de los Habus (que administraba un patrimonio inalienable cuyas rentas se destinaban a obras sociales y religiosas) y el amin al-umana, que recaudaba los impuestos a modo de ministerio de Hacienda. El Jalifa contaba con un consejo consultivo formado por representantes de los territorios y era elegido por el sultán de entre una lista que presentaban las autoridades españolas.

\section{LA TUTELA DEL PATRIMONIO HISTÓRICO EN EL TERRITORIO DEL PROTECTORADO}

En materia de protección y gestión de los recursos patrimoniales existentes en los territorios del Protectorado, debemos tener claro, de acuerdo con la naturaleza jurídica internacional de los derechos y deberes del Estado protector, que éste asume la competencia de los servicios públicos, cuestión, que en lo que nos ocupa, se traduce a que España podía establecer un sistema de gestión y protección del patrimonio, pero que en ningún caso podía trasladar las categorías declarativas de monumentos previstos en la legislación española. De este modo, como veremos a lo largo de este artículo, no se producirán declaraciones de monumentos por la autoridad española sino por la marroquí, y sin embargo España reproducirá miméticamente la organización de los servicios patrimoniales españoles en los territorios sujetos a su protección, y ello precisamente por la potestad que la naturaleza jurídica internacional le otorgaba para la organización y prestación de servicios públicos.

De lo expresado se deduce que la creación de estructuras administrativas de gestión del patrimonio del protectorado responde a idénticos principios y planteamientos que la misma tiene en España. Es por ello, que antes de analizar esas estructuras, debemos referirnos brevemente a la evolución que la tutela del patrimonio había seguido en España, y a la situación en que se encontraba su organización en 1912 y su evolución posterior hasta 1956.

\section{LA EVOLUCIÓN DE LA TUTELA EN ESPAÑA ENTRE 1752-1912.}

Está comúnmente aceptada la Orden de 2 de octubre de 1752, como el inicio de la protección del patrimonio histórico en España. En ella se ordenaba la "Instrucción que ha de observar D. Luis Velásquez de la Real Academia de la Historia, en el viage a que está destinado para aberiguar y reconozer las antigüedades de España”. El "Viaje de las antigüedades de España”, es una de las empresas más importantes del siglo XVIII (Meier 2003. 442). Es también el precedente directo de la Real Cédula de 6 de julio de 1803, que confería importantes competencias a la Academia de la Historia en materia de tutela del patrimonio, como consecuencia de la reorganización que esta institución sufrió en 1792 . Mención especial merece en este proceso evolutivo de la tutela, la Novísima Recopilación de 1805, que recogió la Real Cédula citada y una Instrucción de 26 de marzo de 1802. 
En la Novísima se hace por vez primera una amplia enumeración de objetos y restos en un intento de aproximación al concepto de "monumento antiguo":

\begin{abstract}
"Por monumentos antiguos se deben entender las estatuas, bustos y baxos relieves, de qualesquiera materias que sean; templos, sepulcros, teatros, anfiteatros, circos, naumaquias, palestras, baños, calzadas, caminos, aqüeductos; lápidas ó inscripciones, mosaycos, monedas de qualquiera clase, camafeos, trozos de arquitectura, colunas miliarias; instrumentos músicos, como sistros, liras, crotalos; sagrados, como prefericulos, simpulos, lítuos, cuchillos sacrificatorios, segures, aspersorios, vasos, trípodes; armas de todas especies, como arcas , flechas, glandes, carcaxes, escudos; civiles, como balanzas y sus pesas, romanas, reloxes solares ó maquinales, armilas, collares, coronas, anillos, sellos: toda suerte de utensilio, instrumentos de artes liberales y mecánicas; y finalmente qualesquiera cosas aun desconocidas, reputadas por antiguas, ya sean Púnicas, Romanas, Cristianas, ya Godas, Arabes y de la baxa edad".
\end{abstract}

La Novísima también hacia recaer sobre la Academia toda la competencia sobre los monumentos antiguos.

\footnotetext{
"La Academia quedará agradecida á los buenos patriotas que coadyuven á la ilustración de la Patria por el medio de buscar, conservar y comunicarla los monumentos antiguos arriba nombrados; sin que por eso dexe de satisfacer á los poseedores de las cosas halladas el tanto en que se convinieren, quedando la conducción de ellas á cargo de la Academia”.
}

La guerra de la Independencia y el expolio francés, así como la desamortización produjeron una nueva conciencia hacia el patrimonio como identidad nacional. Un ejemplo de este espíritu es la Cédula del Consejo Real de 2 de octubre de 1818 por la que se dictaban medidas tendentes a lograr la conservación de los restos descubiertos en 1789 en la Cabeza del Griego, en Saelices, la actual Segóbriga o la de 19 de septiembre de 1827, que incorporaba una Orden de 12 de agosto de 1827 , en el que se constataba el deterioro de las ruinas de Itálica. Otra medida importante la constituye la creación del cargo de Inspector de Antigüedades en 1838, habiendo siendo nombrado por Real Orden de 9 de octubre del mismo año para dicha responsabilidad en el ámbito de Andalucía Manuel de la Corte y Ruano, correspondiente de la Real Academia de la Historia, en lo que vendría a representar uno de los primeros jalones en el proceso de paulatina instauración de una administración específica y directamente dedicada a las tareas de protección y gestión patrimonial en Andalucía.

Otra consecuencia de este espíritu serán las Reales Ordenes de 2 de abril y 13 de junio de 1844, por las que se crean las Comisiones Central y Provinciales de Monumentos Históricos y Artísticos a imitación de la Ley francesa de 1830, la llamada Ley Guizot verdadero ejemplo de la administración honoraria que aún perdura entre nosotros. Paralelamente se produce la aparición de los museos, archivos y bibliotecas, que quedaron encargados de recoger los restos del "mayor naufragio" sufrido por nuestros bienes culturales por causa de la desamortización y de proceder a su instalación pública (Villafranca 1998: 31). Ese es el origen de los museos de Granada, Cádiz, Jaén o Sevilla, que ya figuran en la Memoria de 1845 (Madrazo Martín, en Villafranca 1998). La primera estructura de gestión son las Comisiones y los Museos, Archivos y Bibliotecas con un doble objetivo: formar colección con los objetos muebles procedentes de la desamortización y con las piezas y objetos arqueológicos fruto de los hallazgos fortuitos -aparición del Tesoro arqueológico distinto del civil- o de las primeras excavaciones, como en el caso de Itálica con las procedentes de las campañas de Bruna y Espinoza (Verdugo et alii 2003: 76).

Volviendo a las Comisiones de Monumentos, debemos ver en ello la incipiente estructura administrativa de la tutela de los bienes patrimoniales en España, a pesar del inconveniente de su excesivo rasgo honorífico (Alegre Ávila 1994: 47-48). Su creación trae instrumentos muy novedosos como el mandato dirigido a la investigación arqueológica:

\footnotetext{
"La sección tercera cuidará de promover excavaciones en los sitios en donde hayan existido famosas poblaciones de la antigüedad, excitando el celo y patriotismo de los eruditos y anticuarios, recogerá cuantas monedas, medallas, noticias y otros objetos antiguos puedan encontrarse, los clasificar oportunamente y atenderá, en fin, a la conservación de aquellos edificios cuyo mérito los haga acreedores a semejante distinción"
}

Por el Real Decreto de 15 de noviembre de 1855, la Comisión Central y las Provinciales de Monumentos fueron situadas bajo la tutela conjunta de las Reales Academias de la Historia y de Bellas Artes, creándose una Comisión mixta Organizadora de las Provinciales de Monumentos entre ambas Reales Academias de cara al sostenimiento de las labores de coordinación entre las dos instituciones así como con vistas a desempeñar la mencionada labor de tutela de las referidas 
Comisiones Provinciales. La realidad fue una fuerte dependencia de la Comisión Central que desempeñaba el papel de superior jerárquico de las provinciales. Esto trajo como consecuencia su supresión en la Ley Moyano de Instrucción Pública de 1857, que puso al cuidado de la Real Academia de San Fernando la conservación de los monumentos y a las Comisiones bajo su dependencia, lo que supuso integrar en una visión unitaria toda la política educativa y de Bellas Artes (García de Enterria 1983: 578).

Los avatares políticos también influyeron con nuevos impulsos sobre esta materia. La creación de la $\mathrm{I}^{\mathrm{a}}$ República Española produce el Decreto de 16 de noviembre de 1873 , en cuyo preámbulo, escrito por Joaquín Gil Berges ${ }^{1}$, se dice:

"El Gobierno de la República ha visto con escándalo en estos últimos tiempos los numerosos derribos de monumentos artísticos notabilísimos [...]. Précianse todos los pueblos civilizados de conservar con religioso respeto los monumentos que atestiguan las glorias de su pasado [...] prescinden al hacerlo de la significación que el monumento tuvo; y [...] no reparan si es obra de la tiranía o engendro de la superstición". Añadiendo: "Y sería doblemente doloroso que tales atentados se cometieran en pleno régimen republicano. La República no puede ser la destrucción, la República no puede representar el vandalismo [...] no puede consentir esos excesos que la deshonrarian..."

Podríamos considerar esta pieza jurídica, de breve vigencia, como el primer eslabón de una serie de disposiciones que desde una perspectiva moderna intentan establecer un sistema de tutela de los bienes culturales. $\mathrm{Su}$ influencia en la normativa posterior será evidente, en especial en la Ley de Excavaciones de 1911. Pero el periodo republicano fue breve. Sin embargo, la nueva mentalidad va abriéndose paso. Surgen voces que piden una ley general, como es el caso de Demetrio de

1. (Jaca, H., 1834 - Zaragoza, 1920). Abogado, foralista y político republicano aragonés, cursó enseñanza secundaria en las Escuelas Pías de Jaca y luego en Zaragoza, donde hizo carrera de Leyes y se estableció como abogado, llegando a ser uno de los más prestigiosos de la ciudad y de Aragón. En 1868 era cabeza del Partido Demócrata en Zaragoza, por lo que -tras breve encarcelamiento- fue miembro de la Junta Revolucionaria de esta ciudad. Elegido diputado a las Constituyentes de 1869 (por Zaragoza y Huesca, optando por esta última), votó en ellas por la forma republicana. Diputado de nuevo en las Cortes siguientes, y en las Constituyentes de la República (de las que fue vicepresidente), es nombrado ministro de Gracia y Justicia (27-VI-1873) por Pi y Margall y de Fomento (e, interinamente, de Ultramar) en el siguiente gabinete, siendo presidente Castelar: desde el Ministerio de Fomento dicta el Decreto de 16 de noviembre de 1873 los Ríos, excavador de Itálica entre 1860-1880, que se quejaba de la ineficacia de las disposiciones legales y exigía una Ley Especial de Monumentos (De los Ríos 1875: 134). El resultado de estas demandas es la creación de una Comisión encargada de preparar una ley de conservación de las antigüedades, por el Real Decreto de 6 de diciembre de 1883, diez años después del decreto de Gil Berges. En la misma se recogía:

"Se crea una Comisión con el encargo de presentar al Ministro de Fomento las bases de una ley de conservación de antigüedades españolas, comprendiendo bajo este nombre todos los recuerdos de las artes, ciencias e industrias referentes a los diversos pueblos que han habitado en nuestra Península y los documentos importantes para la historia de España"

Lo más destacable del decreto en cuanto a orientaciones para la futura ley era el abordar el asunto de la propiedad de las antigüedades, por lo que consideraba prioritario establecer un procedimiento que regulase el régimen de los descubrimientos arqueológicos, viejo conflicto entre las concepciones del régimen del tesoro del derecho romano que se verá reconocido en el Código Civil de 1889 y el nuevo concepto del bien arqueológico.

Lo cierto es que durante todo el siglo XIX se careció de un corpus legislativo que aclarase conceptos e ideas al respecto. La legislación fue débil dictada con la intención de abordar cuestiones concretas como la de prevenir la salida al extranjero de piezas u objetos; la autorización previa de intervenciones. De todo ello nació la necesidad de contar con una ley general reguladora (Alegre Ávila 1994:47).

El primer resultado es la Ley de Excavaciones y Antigüedades de 7 de julio de 1911 y su Reglamento de 1 de marzo de 1912, aparecido precisamente en el año en que da efectivamente comienzo el Protectorado Español en Marruecos Septentrional (tras la entrada de las tropas españolas -momento cargado de simbolismo- en la ciudad de Tetuán). La ley venía a dotar de una base legal y organizativa estructurada al marco de la labor arqueológica, que se vería reforzada con la creación, de manera contemporánea, de la Junta Superior de Excavaciones y Antigüedades (creada en 1912 y que comenzaría a publicar sus Memorias en 1916) así como por el nuevo impulso a las ya existentes Comisiones Provinciales de Monumentos que se plasmaría mediante el Real Decreto de 11 de agosto de 1918 (Maier 2004: 100 ss.; López 2004: 363 ss.).

Así pues, en el lento camino de construcción de las estructuras de protección y gestión del Patrimonio Histórico español serán los siglos XIX y XX los 
que vengan a sentar los cimientos, primero, y los muros, después, de un edificio el crecimiento de cuya fábrica se encuentra siempre (aún hoy) en proceso. De este modo, este proceso se vería plasmado en diferentes normativas e instituciones que irían viendo la luz de manera paulatina; si el XIX fue época de consolidación y aparición de instituciones (caso de las Reales Academias o las Comisiones Provinciales de Monumentos), el siglo XX habría de ser -y ello desde sus mismos principios- alumbrador de normativas legales; así, por el Real decreto de 1 de junio de 1900 (desarrollado y complementado por el R.D. de 14 de febrero de 1902) se determinaba la formación del Catálogo Monumental y Artístico de la Nación, mientras el Real Decreto de 29 de noviembre de 1901 aprobaba el Reglamento de los Museos Arqueológicos del Estado servidos por (y encomendados a) el Cuerpo Facultativo de Archiveros, Bibliotecarios y Arqueólogos (Gaceta 337, de 3 de diciembre de 1901)

Tras estos pasos iniciales y previos, la Ley de Excavaciones Arqueológicas de 7 de julio de $1911^{2}$ (y el desarrollo de la misma en el Reglamento de 1 de marzo de 1912 acerca de excavaciones y antigüedades, publicado en la Gaceta, 65, de 5 de marzo de 1912) venía finalmente $-y$ tras diversos intentos anteriores no culminados por el éxito (como los de 1876 y 1883; Maier 2004: 115-116) - a proporcionar una base tangible tanto en lo legal como desde la perspectiva organizativa para las labores arqueológicas de campo y de gabinete, que se vería complementada con la creación de la Junta Superior de Excavaciones y Antigüedades (creada en originalmente en 1912 y que publicaría sus Memorias anuales a partir de 1916), con la Ley de Monumentos Arquitectónicos y Artísticos de 1915 (de 4 de marzo de 1915, que instituye el procedimiento administrativo para la declaración de los monumentos), así como por el relanzamiento en el año 1918 de las Comisiones Provinciales de Monumentos (reactivación impulsada efectivamente mediante un Real Decreto de 11 de agosto de 1918 y su Reglamento de 11 de octubre de 1918); éstas, las Comisiones Provinciales, habiendo sido creadas originalmente en la primera mitad del siglo XIX bajo el gobierno de Isabel II, por Real Orden de 13 de junio de 1844, contaban a su vez con algunos precedentes en materia de protección y cuidado del Patrimonio datados en el mismo reinado tales como el cargo de Inspector de Antigüedades (creado en 1838, y para cuyo desempeño

2. Gaceta, 189, de 8 de julio de 1911; entre otros principios, esta Ley establece la primacía del interés público sobre el privado, señala la propiedad del Estado sobre los hallazgos casuales o los encontrados al demoler edificios, regula el derecho de otorgar los permisos de excavación, penalizando las que se realizaran sin autorización. en Andalucía fuera nombrado Manuel de la Corte y Ruano, miembro correspondiente de la Real Academia de la Historia de España (la R.A.H.), por R.O. de 9 de octubre de ese mismo año 1838); nos encontramos de esta forma ante los que cabe considerar que vendrían a representar y constituir los primeros pasos de la paulatina instauración de una administración (como tal) dedicada a la protección y gestión patrimonial en España (y, por ello, en su extremo Sur, en Andalucía).

Las Comisiones Provinciales de Monumentos, tras dos decenios iniciales que habrían transcurrido con no excesiva actividad, serían inicialmente reorganizadas en 1864-65 (y emplazadas bajo la tutela conjunta de las Reales Academias de la Historia y de Bellas Artes), quedando de este modo situadas bajo la tutela conjunta de ambas Reales Academias (de la Historia y de Bellas Artes de San Fernando), creándose como consecuencia de ello una Comisión Mixta Organizadora de las Provinciales de Monumentos (CMOPM) entre ambas Reales Academias de cara al sostenimiento de las labores de coordinación entre ambas instituciones así como con vistas a desempeñar la mencionada labor de tutela de las referidas Comisiones Provinciales (objetivo fundamental de la mencionada Comisión Mixta); como venimos apuntando, estas Comisiones Provinciales de Monumentos se verían entonces dotadas (tras la puesta en marcha de otras medidas emprendidas a principios de la década de los ochenta del siglo XIX) ${ }^{3}$ de un nuevo Reglamento (el citado de 11 de octubre de 1918), bajo Alfonso XIII (Maier 2004: 100 ss.; López 2004: 363 ss.).

La región de Tetuán en el norte de Marruecos no se encontraría al margen de esta reglamentación legal y administrativa de la gestión del Patrimonio Arqueológico dimanada del Reino de España al cual se encontraba administrativamente ligada. Si a partir de 19121913 comenzaría a hacerse efectivo el control por parte de España de la zona septentrional de Marruecos bajo la forma y fórmula del Protectorado ${ }^{4}$, ya desde $1880^{5} \mathrm{se}$

3. E.g., el Reglamento de las Comisiones Provinciales de Monumentos Históricos y Artísticos publicado en Madrid (en la "Imprenta y Fundición de Manuel Tello"), en el año 1882; cfr. Parodi (2009: 118)

4. Cfr. sobre el particular el trabajo de Lamouri (2007: 207220); de acuerdo con el profesor Lamouri (de la Faculté des Sciences Juridiques, Économiques et Sociales, Université de Rabat), Francia habría impuesto su protectorado a Marruecos ("...impose au Maroc...") en marzo de 1912 para posteriormente concluir un acuerdo con España en noviembre de dicho año, por el que se dividirían las dos zonas de influencia y administración del entonces sultanato marroquí (Lamouri 2007: 212).

5. Recordemos tan sólo que la Conferencia de Berlín, por la que las potencias europeas sancionaron y decidieron el "reparto" de África tuvo lugar en fecha tan próxima a la Conferencia de Madrid como 1885. 
habrían dado los primeros pasos diplomáticos (tras la "Guerra de África" de los años sesenta del siglo XIX sostenida por España en el país magrebí y que se inserta en el marco de la política de intervención neocolonial emprendida bajo el reinado de Isabel $\mathrm{II}^{6}$ ) para la "internacionalización" de los asuntos de Marruecos, o -dicho de otro modo- para la intervención de las potencias extranjeras (fundamentalmente Gran Bretaña, Francia, Alemania y España, las más interesadas en dicho ámbito geoestratégico, siendo Alemania la gran perjudicada en sus intereses tras el acuerdo entre Francia y Gran Bretaña) en la política marroquí.

La consecuencia más relevante de la Conferencia de Madrid de 1880 habría de ser precisamente la del establecimiento (más o menos tácito) del papel preponderante de Francia y España en Marruecos; en este sentido y en la misma línea, otras potencias europeas vinieron -en los años siguientes a dicha Conferenciaa reconocer este status quaestionis; de este modo Italia declaró pública y formalmente su desvinculación (su renuncia a posibles intereses especiales) respecto al entonces sultanato xerifiano en el año $1902^{7}$, mientras Francia y Gran Bretaña vinieron a reconocer mutuamente sus intereses preferentes en Marruecos y Egipto, respectivamente, por la declaración anglo-francesa de abril de 1904, acuerdo al que vino a seguir el tratado secreto hispano-francés de octubre de 1904 por el que España ratificaba y se adhería a la mencionada declaración anglo-francesa de abril de 1904, al tiempo que Francia y España reconocían sus mutuos intereses en dos áreas marroquíes de las que (sin entrar en otros detalles de mayor concreción geográfica) la costa norte de Marruecos quedaba englobada en el área de influencia española reconocida por la república francesa, siendo este acuerdo completado por otro suscrito por ambas potencias europeas e igualmente secreto, datado en 1905, que ampliaba las disposiciones del anterior pacto

6. En este sentido, recuérdense otras iniciativas del mismo período y de similar naturaleza como la intervención española en México en apoyo a Napoleón III y al fugaz Imperio de Maximiliano I de Habsburgo, la ayuda de España a Francia (prestada desde las Filipinas) en campañas del país galo en Indochina (Annam y Cochin), la efímera reintegración de Santo Domingo a soberanía española o, igualmente en ámbito Hispanoamericano, la guerra hispano-peruana de 1865 .

7. Renunciando de este modo a sus posibles intereses sobre el África del Noroeste, mientras los continuaría sosteniendo en relación con otros territorios del septentrión africano, caso de Libia, por entonces territorio sujeto aún a la autoridad de la Sublime Puerta Turca, y que, tras la breve guerra de 1911 entre Italia y Turquía, habría de pasar a la dominación italiana (mantenida hasta la Segunda Guerra Mundial); para la postura del gobierno italiano en la Conferencia de Algeciras (francamente conciliadora con Gran Bretaña, Francia y España), cfr. del Valle (2007: 325-346). hispano-galo con cuestiones de mayor detalle relativas a la organización de asuntos tales como la policía marroquí, los puertos, el contrabando de armas o la creación de una banca de negocios (aspectos todos los cuales se verían recogidos posteriormente en los tratados de 1912 entre Marruecos, Francia y España) ${ }^{8}$.

La referida Conferencia de Madrid de 1880, así como los movimientos diplomáticos que vemos desarrollarse en torno a la "cuestión marroquí" en el primer lustro del siglo XX cristalizarán con la Conferencia de Algeciras de 1906; un antecedente inmediato de dicha Conferencia Internacional (amén del representado por los acuerdos franco-británico y franco-español de 1904, Entente Cordiale incluida) habría de buscarlo en la visita del emperador alemán, Guillermo II a Tánger en 1905, y su propuesta al Sultán marroquí, aceptada, retomada y relanzada por el soberano magrebí acerca de la celebración, precisamente, de un encuentro internacional de alto nivel en el que el argumento principal habría de ser precisamente la "Cuestión de Marruecos"; de la conjunción de iniciativas diplomáticas europeas y de las maniobras de la diplomacia alemana en torno al territorio marroquí habría de resultar la celebración de la Conferencia Internacional de Algeciras en $1906^{9}$, en la que -en líneas generales- vendría a sancionarse la situación planteada precisamente por los movimientos diplomáticos triangulares anglo-franco-españoles precedentes, esto es, el status quo y el equilibrio entre las esferas inglesa y francesa en el Norte de África, que se plasmaría a su vez a través de la distribución de los respectivos espacios de influencia entre Francia y España en Marruecos ${ }^{10}$.

8. Lamouri (2007: 214-215). Sólo Alemania (de entre las potencias europeas activamente "interesadas" en el Mahgreb occidental: la postura diplomática de Austria-Hungría vendría más determinada por su alianza con el Imperio Alemán que por sus propios intereses, más dirigidos hacia el Mediterráneo Oriental) mantendría sus posiciones (y la defensa de sus intereses) hasta la Conferencia de Algeciras de 1906; de hecho, el II Reich ya el año antes de la visita del emperador Guillermo II a Tánger (visita efectuada en 1905) había denunciado el acuerdo secreto hispano-francés suscrito en ese mismo 1904 (el "secreto" del tratado habría durado, como tal, pues, muy poco tiempo); del Valle (2007: 329-330). En otro orden de cosas, podemos considerar que la Conferencia de Madrid de 1880 se inserta en el mismo espacio diplomático internacional de finales del XIX que vería igualmente gestarse el Congreso de Berlín de 1885, reunión internacional en la que se determinaron los términos del "reparto" de la "tarta" (sic) africana en manos de las potencias coloniales europeas.

9. Verdú y Torrejón (2007: 44).

10. Para las cuestiones técnicas específicas de la Conferencia de Algeciras, así como para los términos dimanados del Acta de la misma, cfr. Verdú y Torrejón (2007: 46 ss.); los mismos autores señalan el rol de la Conferencia de Algeciras como espacio de consolidación de las alianzas europeas de principios del siglo XX (ibid.: $55 \mathrm{ss}$.). 
Una vez puestos en funcionamiento los resortes de la administración del Protectorado de España sobre el Norte de Marruecos ${ }^{11}$ se irá asistiendo a la evolución y marcha en paralelo del establecimiento de normativas, reglamentos, instituciones y organismos de gestión del Patrimonio, en una y otra orillas del Fretum Gaditanum a partir del impulso inicial otorgado a este proceso, un primer impulso que debemos establecer precisamente en 1911 y que se vería plasmado efectivamente a través de la Ley de Excavaciones de dicho año (un texto legal promulgado tras las resoluciones de la Conferencia de Algeciras de 1906, pero antes de la materialización del Protectorado y el control hispano sobre Tetuán a finales de 1912 y principios de 1913); un paso siguiente sería el del 30 de abril de 1916, fecha en que se emite el Real Decreto (firmado por Alfonso XIII) mediante el que se crea la Junta Superior de Estudios Históricos y Geográficos de Marruecos, organismo adscrito al Ministerio de Estado del gobierno de España.

Esta Junta (cuyos trabajos estaba previsto que hubieran de centrarse de forma preferente pero no necesariamente exclusiva en las zonas del Protectorado bajo control de la coadministración hispano-marroquí) habría tenido como una de sus primeras y principales tareas, atribuciones y deberes el "trazar el plan general de exploración geográfica y arqueológica y de investigaciones y estudios históricos", intención ambiciosa para la época y los medios (materiales y económicos) disponibles (BRAH LXVIII, 1916. Documentos Oficiales II, pp. 642-645), como ya hemos señalado en otro $\operatorname{lugar}^{12}$. En 1919 se crearía la Junta Superior de Monumentos Artísticos e Históricos, bajo cuya responsabili-

11. Tras unos años de gran inestabilidad en Marruecos (luego de la firma del Acta de Algeciras, en abril de 1906), con el derrocamiento del sultán Abd Al Aziz por su hermano, Muley Hafid como acmé de la situación, entre 1911 y 1912 se asistiría a la intervención militar de Francia, de una parte, y de España, de otra (con episodios bélicos como los del Barranco del Lobo o el Monte Gurugú, por ejemplo, por parte hispana), una acción militar que llevaría a la toma de Fez, Meknes y Rabat por Francia o de Tetuán por España, y que se vería seguida por el reconocimiento definitivo por parte marroquí del protectorado francés (30 de marzo de 1912), así como por el no menos definitivo acuerdo entre Francia y España para el reparto de sus zonas de influencia en Marruecos (27 de noviembre de 1912), quedando Tánger bajo un Estatuto Internacional (refrendado a posterior por un acuerdo de 1923); cfr. Verdú y Torrejón (2007: 62-63); para la relación desigual establecida por los acuerdos de 1912 entre Francia y Marruecos, de una parte, y entre Francia y España, de otra (con una cierta preeminencia de Francia en dicho contexto, ya que la relación entre los reinos magrebí y español pasaría por la intermediación gala), cfr. Remacha Tejada (2007: 68 ss.)

12. Sobre las funciones y objetivos de dicha Junta y sobre las concepciones de "exploración” y "descubrimiento" (desde un plano geográfico) albergadas en la propia concepción de la misma, vid. $\mathrm{Pa}$ rodi (2009: $118 \mathrm{ss}$ ). dad quedarían las labores de naturaleza arqueológica, como las que poco después (en 1921) se iniciarían en el emplazamiento de Tamuda, junto a Tetuán, bajo la responsabilidad de César Luis de Montalbán y Mazas, nombrado asesor técnico de la antedicha Junta Superior de Monumentos Artísticos e Históricos ${ }^{13}$. No debe ser fruto de la casualidad que mientras en el territorio peninsular se estuvieran relanzando y potenciando las Comisiones Provinciales de Monumentos (en 1918, mediante el R.D. y el Reglamento mencionados supra), en los territorios marroquíes del Protectorado se crease en 1919 (sólo un año después) la referida Junta Superior, organismo de diferentes denominación y formato pero tendente a la misma actividad.

La normativa dimanada por el representante del Sultán en el Protectorado, el jalifa (y su órgano de gobierno, el Majzén), vendría a complementar a la española; así, como vemos, la autoridad marroquí emitió un Decreto Vizirial que creaba la Junta Superior y las Juntas locales (dependientes de la anterior) para la conservación de monumentos artísticos e históricos de la Zona del Protectorado el 22 de abril de $1919^{14}$, con lo que se procuraba proporcionar (cuando menos inicialmente sobre el papel) una estructura regional y una red local a la gestión del Patrimonio Arqueológico, Monumental, Histórico y Artístico en el Norte de Marruecos ya desde principios del siglo XX (cfr. Boletín de la Real Academia de la Historia-BRAH-LXXIV, 1919. Cuaderno VI, junio. Documentos Oficiales II, "Decreto Vizirial creando la Junta Superior y Juntas locales de Monumentos Históricos y Artísticos en Marruecos", pp. 546-549); del peso que se pretendía conceder a esta Junta Superior da cuenta el hecho de que estuviera presidida por el Gran Visir, quedando integrada por el Secretario General de la Alta Comisaría así como el Delegado de Asuntos Indígenas y el de Fomento de los Intereses Materiales, contando como asesores con otros responsables de la administración del Protectorado como el arquitecto de la Delegación de Fomento, un jefe del ejército, y sendos académicos correspondientes de las Reales Academias Españolas de la Historia y de la de Bellas Artes. El articulado de este texto legal recogía entre otras obligaciones de la administración la de velar por el cumplimiento del anterior Dahir de agosto de 1913 (15 de ramadán de 1331); igualmente era deber de la administración el catalogar los bienes de la cultura (a los que se denomina genéricamente "mo-

13. F. Valderrama Martínez, Historia de la acción cultural de España en Marruecos (1912-1956). Alta Comisaría de España en Marruecos. Editora Marroquí, Tetuán, 1956, pp. 721-ss.

14. 20 de Rayeb de 1337. 
numentos artísticos e históricos", quizá siguiendo la nomenclatura y terminología españolas), especificándose el recurso a la fotografía (en 1919) para llevar a cabo estas labores de catalogación; también se señala la conveniencia de aunar estas fotografías y los bienes muebles encontrados (al hablar de éstos se les engloba bajo la denominación de "objetos artísticos, inscripciones, lienzos, medallas, monedas, etc.”, sin mayores cuestiones de detalle) de cara a conformar y crear "pequeños museos" locales (art. 1); parte de la responsabilidad sobre esta materia (la obtención y la conservación -y con esta última, la protección- de los bienes de la cultura, inmuebles y muebles) recaía sobre las autoridades locales (municipales) -arts. 2-4 ${ }^{15}$.

Este Decreto Vizirial de 1919 había sido ya precedido de un Dahir de 18 de agosto de 1913 (15 de ramadán de 1331), "Relativo a la conservación de los monumentos y objetos artísticos e históricos", igualmente emitido por las autoridades marroquíes y tendente a garantizar la responsabilidad de los resortes de la administración marroquí (así como de los dirigentes locales) respecto a la preservación del Patrimonio Histórico, Arqueológico y Monumental, situando estas responsabilidades directamente bajo el ámbito de mandato y la jurisdicción del jalifa ${ }^{16}$. Estos documentos oficiales

15. Asesor de la Junta General por la de San Fernando sería Mariano Bertuchi, Inspector de Bellas Artes del Protectorado y académico de las BB.AA.; en esta línea de protección de los Monumentos hay que insertar las labores de investigación de carácter arqueológico emprendidas bajo la administración del Protectorado y encomendadas, en una primera instancia, a César Montalbán, así como iniciativas como la emprendida por Bertuchi (en su calidad de Inspector de BB.AA. -recordemos que la Inspección de Arqueología se consolidaría a la llegada de Quintero, en 1939-1940) con la moción presentada por la Inspección de Bellas Artes y Artes Indígenas en mayo de 1927 solicitando la desaparición de viviendas y almacenes sitos sobre algunos Monumentos históricos; más allá de lo que pudiera considerarse como una intervención puntual, la Inspección de BB.AA. y AA.II. solicitaba igualmente que se sometiera a su evaluación y supervisión cualquier obra a realizar en el interior de las medinas y juderías, recogiendo así la letra y el espíritu de los Dahires de 1913 y 1919 y anticipándose al Reglamento de 1941 (reformado en 1955); Valderrama (1956: 735 ss.).

16. En este Dahir se apelaba a la calidad ética y moral de los buenos creyentes musulmanes para proteger el Patrimonio Histórico, sosteniendo, entre otros argumentos, que es propio del buen creyente proteger las huellas del pasado; la protección del Patrimonio entraría de este modo directamente en el ámbito de lo moral, si bien es preciso no obviar que se trataba de una disposición emitida por las autoridades estatales marroquíes: el Majzen, órgano de gobierno del Sultán y del jalifa como representante de aquél, no es específicamente un organismo religioso, si bien el Sultán es el príncipe de los creyentes $\mathrm{y}$, como tal, aúna en su persona y disposiciones la potestas laica (estatal) con la auctoritas religiosa; al mismo tiempo, se establecía la protección del Majzén sobre los monumentos, quedando supeditada la propiedad privada al interés público (sin perjuicio de los derechos de los propietarios): de este modo, el artículo 2 del Dahir establece serían seguidos por otras disposiciones, como otro Decreto Vizirial (que ampliaba los contenidos del emitido en 1919, v.g. en lo relativo a la composición de las Juntas Superior y Locales, ampliadas en esta segunda disposición), emitido el 11 de diciembre del año $1920^{17}$; en 1921 un Dahir (de 16 de mayo) ampliaría la composición de la Junta mediante el nombramiento de nuevos vocales, entre los que se contaría el entonces comandante de Estado Mayor del ejército español Juan Beigbeder Atienza, quien andando el tiempo llegaría a convertirse en Alto Comisario Español en Marruecos ${ }^{18}$.

Más adelante, un Real Decreto emitido por la autoridad española con fecha de 23 de marzo de 1927 creó la "Junta de Investigaciones Científicas de Marruecos y Colonias", que vino a englobar en su ámbito de acción a la primitiva Junta creada por el precedente R.D. de 1916 (organismo que hasta entonces se habría mostrado poco operativo), mientras, y en lo que se refiere al Patrimonio árabe escrito, un Dahir emitido por las autoridades marroquíes el 1 de febrero de 1938 aprobó la creación de una comisión de investigación encargada de catalogar las obras literarias manuscritas existentes en la Zona del Protectorado ${ }^{19}$; en 1938 se creaban la Biblioteca General y la Hemeroteca de Tetuán,

que si bien el Majzén podía efectuar “...por su cuenta (...) los trabajos necesarios a la conservación del monumento...", ello debía hacerse “...previo aviso al propietario...", el cual en caso de verse perjudicado por la ejecución de los trabajos de salvaguarda, tendría “... derecho a ser indemnizado..." (Valderrama 1956: 734 ss.); es, así pues, y según se desprende de las normativas administrativas y legales de la época, la autoridad marroquí la que se reserva la potestad sobre los "monumentos históricos y artísticos" (públicos o privados) existentes en territorio del Sultanato, quedando de este modo los "monumentos" sujetos a la soberanía del Sultán (que apela en su defensa y salvaguarda incluso a su autoridad religiosa como príncipe de los creyentes) y a la coadministración hispano-marroquí, en el caso del Norte de Marruecos.

17. 29 de Rabia el Auel de 1339; documento publicado en el Boletín Oficial de la Zona del Protectorado Español en Marruecos. Año IX. No. 1, 10 de enero de 1921. Madrid (Imprenta del Ministerio de Estado), 1921, pg. 8 .

18. Valderrama (1956: 737); sería precisamente el ya general Beigbeder quien concedería a Pelayo Quintero Atauri el correspondiente permiso para permitirle visitar “...las plazas de soberanía y Zona de Protectorado de España en Marruecos...", señalando además que la visita de este arqueólogo obedecía a "...realizar una Comisión científica..." encomendada a éste por el propio Alto Comisario (i.e., el mismo general Beigbeder Atienza), documento fechado en Tetuán el 16 de julio de 1939; una addenda a este documento firmada por el Gobernador Civil de Cádiz el 28 de julio de ese mismo año señala que Quintero iría “.... acompañado de su Sra. Da. Juana María Hidalgo Ruiz" (Archivo del Museo de Tetuán); cfr. Parodi (2008: 82).

19. Valderrama (1956, especialmente 814 ss.) reproduce el texto del Dahir de 1 de febrero de 1938 por el que se crea la referida Comisión Investigadora, origen del Instituto General Franco de Estudios e Investigación Hispanoárabe, que habría contado con identidad presupuestaria $-\mathrm{y}$ con estado oficial como tal organismo- desde 
mientras en 1939 se hacía lo propio con el nuevo Museo Arqueológico tetuaní (instalaciones éstas inauguradas finalmente en julio del año $1940^{20}$ ). Otra referencia obligada es la constituida por el Museo Marroquí (también denominado "Museo de Arte Indígena" u "Hogar Musulmán"); la creación de un espacio museístico específicamente destinado a albergar objetos de un valor tradicional o de un carácter etnológico está directamente relacionada con la sujeción por el jalifa a su autoridad y ámbito de administración de los bienes de la cultura, tanto arqueológicos como tradicionales (mediante el Dahir de 18 de agosto de 1913); de esta forma, la creación del Museo Marroquí vendría a equiparar los elementos de la cultura material preislámica (estudiados por arqueólogos españoles y guardados en el Museo Arqueológico) con los de la cultura islámica (custodiados en el Museo Marroquí); este Museo vio aprobada su creación en febrero de 1928, quedando efectivamente constituido en la segunda mitad de ese mismo año con una ubicación provisional (una sede en alquiler) y bajo la responsabilidad de Mariano Bertuchi (vid. supra, asesor de la Junta Superior de Monumentos Históricos y Artísticos e inspector general de Bellas Artes del Protectorado); finalmente sería decidido su traslado en 1946, un traslado que se materializó en juniojulio de 1948 a la sede que ocupa aún hoy ${ }^{21}$.

Cabe señalar cómo de forma paralela a cómo en 1918-1919 se habían potenciado (caso de las Comisiones Provinciales españolas) o creado (caso de la Junta Superior de Monumentos Artísticos e Históricos) diferentes órganos en España y Marruecos septentrional, la antedicha "Junta de Investigaciones Científicas de Marruecos y Colonias", creada en 1927 en Marruecos, habría sido precedida en el tiempo por el Decreto-Ley español de 9 de agosto de 1926, sobre la Protección, Conservación y Acrecentamiento de la Riqueza Artística, en una manifestación más de la existencia de una nítida relación entre las estructuras españolas al Norte y Sur del Estrecho de Gibraltar ${ }^{22}$.

Por lo que atañe más específicamente al Museo Arqueológico de Tetuán, cabe mencionar cómo se registraba ya correspondencia entre esta institución y la

el ejercicio presupuestario de 1941, siendo Tomás García Figueras su presidente).

20. Cfr. Zouak (2006: 343-346)

21. Valderrama (1956: 741 ss.).

22. El Decreto-Ley de 9 de agosto de 1926, sobre la Protección, Conservación y Acrecentamiento de la Riqueza Artística matiza y modifica la Ley de 4 de marzo de 1915, define el "Tesoro Artístico Nacional" como "el conjunto de muebles e inmuebles dignos de ser conservados para la nación por razones de arte y de cultura", definiendo los bienes inmuebles como "las edificaciones o conjuntos de ellas, los sitios y lugares de reconocida y peculiar belleza”.
Comisión Provincial de Patrimonio de Cádiz ya en los primeros años 20 del siglo XX. Así, podemos señalar cómo en la sesión del 10 de julio de 1923 de la referida Comisión Provincial de Monumentos de Cádiz, la presidencia de la misma, ejercida por Pelayo Quintero de Atauri, dio a conocer a los miembros de la misma una carta dirigida a la referida Comisión por el Director del Museo Arqueológico de Tetuán (sic) en la que éste informaba a la misma acerca de la existencia de "vestigios de seguros descubrimientos de Arqueología en terrenos de propiedad particular de la ciudad de San Roque", lo que deja de manifiesto las relaciones de la referida Comisión, es de entender (y de su entonces presidente, Pelayo Quintero) no sólo en el ámbito provincial gaditano, sino incluso más allá del Estrecho de Gibraltar; tales circunstancia y carta podrían precisamente haber obedecido a la llegada de Montalbán y Mazas a tierras tetuaníes y al comienzo de sus trabajos arqueológicos en dicha región norteafricana, amén de a su voluntad de proyección en el ámbito peninsular hispano.

Este dato (que aparece en el Boletín de la Comisión Provincial de Monumentos de Cádiz. 2a. Época. Núm IV. Años 1923 y 1924, pg. 16) resulta interesante por varios motivos: refleja las conexiones del ámbito gaditano (esto es, peninsular) existentes ya en 1923 con Tetuán y el Norte de Marruecos; a la vez muestra claramente la existencia de relaciones entre C.L. de Montalbán y P. Quintero desde los años 20 del pasado siglo $\mathrm{XX}$, algo muy posible dado que, contemplada la cuestión con la perspectiva necesaria, se observa que ambos estudiosos eran responsables de las actividades arqueológicas (una tarea común) en dos regiones limítrofes: el Sur de Europa (Quintero) y el Norte de África (Montalbán), las dos orillas del Estrecho; es de especificar que la referida Comisión Provincial de Monumentos gaditana facultó a su presidente -Quintero Atauri- para hacer gestiones cerca del propietario de aquellos terrenos sanroqueños, destinando a tales fines las 2.000 pesetas (de 1924) destinadas originalmente a la continuación de las excavaciones que se venían realizando en el Barrio de San Severiano de la capital gaditana; finalmente, resulta asimismo interesante asimismo este apunte porque da a conocer a la existencia de un "Museo Arqueológico de Tetuán" ya en fecha tan temprana como el año 1923, y ello resulta especialmente significativo porque la versión tradicionalmente aceptada y generalmente asumida y difundida es la de que el Museo Arqueológico tetuaní fue inaugurado (ex novo nullaque, por así decirlo) en julio de 1940, bajo la dirección de Pelayo Quintero Atauri. Sin embargo, como vemos, ya 17 años antes de dicha fecha (1940) y varios años antes de 1931 
(primera constitución del Museo, vid. infra) debía existir una instalación (con mayor o menos merecimiento) que gozase de tal denominación.

Sería a raíz de la puesta en marcha de los trabajos de campo sistemáticos (plus minus) por C.L. de Montalbán en los años 20, que se observaría la necesidad de contar con un Museo que pudiera albergar adecuadamente los materiales hallados en dichas prospecciones y excavaciones (materiales que hasta entonces eran almacenados en distintas dependencias de las ciudades de Larache y Tetuán). Vistas las circunstancias que incurrían, se decidió habilitar como Museo unas dependencias en un edificio de la calle de Mohammed Torres (el entonces $\mathrm{n}^{\circ} .7$ ), en Tetuán, en las que habría quedado instalado el Museo en noviembre del año 1931; de todos modos, alguien debió tener la responsabilidad de la dirección de dicho Museo (aun cuando las instalaciones de la calle Mohamed Torres no estuvieran en activo hasta finales de 1931) en 1923, cuando se registra la correspondencia a la que venimos haciendo referencia, y ese "alguien" debió más que posiblemente ser César L. de Montalbán); en el año 1938 se tomó la decisión finalmente del traslado de estas dependencias, al resultar ya insuficientes las citadas instalaciones, y en 1939 iniciaron las obras del nuevo Museo, construido en la calle Mohammed ben Hossain, en la intersección entre las áreas de influencia de las zonas urbanas del Ensanche español y la Medina de Tetuán.

El nuevo Museo Arqueológico de Tetuán, inaugurado el 19 de julio de 1940 (Zouak, loc. cit.), tuvo un primer director en la persona de Pelayo Quintero desde casi un año antes del momento de su inauguración, esto es, desde el mes de octubre de 1939, fecha del nombramiento del mismo (quien había sido nombrado a la vez Inspector de Excavaciones y director del Museo Arqueológico de Tetuán), en sustitución de César Luis de Montalbán, que había cesado en sus funciones (probablemente por motivos políticos) al inicio de la Guerra Civil española, ya en julio de 1936 (y quien no volvería a recuperar algunas de dichas funciones -en el ámbito occidental de la zona del Protectorado, con sede en Larache- hasta la llegada de Quintero Atauri a tierras de Marruecos) ${ }^{23}$.

Con las instalaciones puestas en marcha en 1940, bajo la dirección de Pelayo Quintero, se conseguiría conformar un primer Museo funcional, que sirviera no sólo como "depósito de colecciones", sino, y de la mano del desempeño de su director, que al mismo tiempo ocupaba el cargo de Inspector General de Excavaciones del Protectorado, como núcleo vinculado a

23. Cfr. Parodi (2008: 84 ss.). la investigación arqueológica de campo, como matriz y motor de la investigación sobre el terreno. Igualmente, y desde 1943 (año en el que los Museos de la clase y categoría a la que estaba adscrito el de Tetuán -los no servidos por el Cuerpo Facultativo de archiveros, arqueólogos y bibliotecarios- se incorporaron anualmente al conjunto de las Memorias de los Museos Arqueológicos Provinciales de España), la dirección del Museo tetuaní cumplió estrictamente con el procedimiento, de forma que en los años en los que se mantuvo Quintero al frente del Museo de Tetuán (esto es, hasta su fallecimiento en octubre de 1946), esta institución estuvo siempre representada en el número correspondiente de la periódica edición de las referidas Memorias ${ }^{24}$.

La ya antigua Ley de 1911 sería finalmente sustituida por la Ley de 1933, la "Ley del Patrimonio (o del Tesoro) Artístico Nacional”, del 13 de mayo de 1933 (aparecida en la Gaceta de 25 de mayo de dicho año $1933)^{25}$, y desarrollada mediante el Decreto de 16 de abril de 1936 que recogía el Reglamento para la aplicación de la referida Ley del Tesoro Artístico Nacional ${ }^{26}$; es de señalar que esta normativa republicana (que recoge las bases legales sentadas desde 1901) continuaría en funcionamiento durante la dictadura franquista, de manera que sólo se vería modificada más dos décadas después de su aparición, con la promulgación de la Ley de 22 de diciembre de 1955 sobre Defensa, Conservación y Acrecentamiento del Patrimonio HistóricoArtístico Nacional ${ }^{27}$.

Junto a las instituciones, órganos y entidades hasta ahora mencionados, y en esta misma línea de creación de organismos que dotasen institucional y administrativamente de contenido a la protección del Patrimonio en el Norte de Marruecos, convirtiéndose en los ejecutores de la misma, el 24 de abril de 1941 se creó, desde la Alta Comisaría española en el Protectorado, el Patronato de Investigación y Alta Cultura de Marruecos ${ }^{28}$, en

24. Parodi (2008: 63-92).

25. La cual, entre otras cuestiones novedosas presentaba algunas como la incorporación de los planteamientos surgidos en la Conferencia de Atenas de 1931, la inclusión en la misma del debate internacional en torno a la Cultura Patrimonial así como la creación de la Junta Superior del Tesoro Artístico (que modifica -y sustituye- a organismos anteriores con el mismo objeto y función).

26. Gaceta del 17 de abril de 1936.

27. Publicada en el ya B.O.E. (Boletín Oficial del Estado) de 25 de diciembre de 1955 .

28. La creación de este Patronato proporciona el que quizá constituya uno de los más nítidos ejemplos de la coadministración en el marco del Protectorado: creado en 1941 por una Ordenanza del Alto Comisario (administración española), esta Ordenanza sería modificada por un Dahir del Jalifa (administración marroquí) de 1 de julio de 1953 (19 y de Chual de 1372); significativamente, los artículos 1 y 2 de este Dahir de 1953 serán la base para el articulado del 
el cual quedaría integrada la Junta Superior de Monumentos, mientras el 30 de abril de ese mismo año (con menos de una semana de lapso entre una y otra circunstancias) se reglamentó el funcionamiento de la Junta Superior y las Juntas Regionales y Locales, adaptando dicho funcionamiento a las normas rectoras del Patronato citado. El Patronato (creado en 1941 y reformado en 1953) contaba, entre los instrumentos estructuralmente dispuestos para su acción, con los siguientes organismos (art. 3 del Dahir de 1953): las Juntas Superiores, Territoriales y Locales de Monumentos Artísticos e Históricos, la Inspección General de Excavaciones de la Zona (con los directores de excavaciones y el Museo Arqueológico), la Biblioteca General del Protectorado, la Hemeroteca del Protectorado (sitas en Tetuán), las Bibliotecas Populares, el Archivo Fotográfico y el Archivo General del Protectorado, el Museo Etnológico, el Conservatorio Hispano-Marroquí de Música, los Institutos de Investigación "Muley Hassan" y "General Franco" así como la Inspección de Bellas Artes de la Zona ${ }^{29}$.

Tras media docena de años en vigor, el Reglamento (de 30 de abril de 1941) de las Juntas Superior, Territoriales y Locales de Monumentos sería reformado en primera instancia en octubre de 1947, para sufrir una nueva modificación (para adaptarlo más estrechamente al articulado del Patronato, dispuesto como hemos visto por Dahir de julio de 1953) mediante Dahir de 24 de septiembre de 1955 (7 de safar de 1375) ${ }^{30}$; mediante esta nueva articulación (dispuesta en 14 puntos), la última emitida en el marco de coexistencia de la doble administración del Protectorado, las Juntas Superior y Locales de Monumentos Artísticos e Históricos (bajo cuya denominación se encontraban las medinas, las murallas y sus puertas, los castillos, las alcazabas, las mezquitas y las fuentes) veían ratificada su integración en el Patronato de Investigación y Alta Cultura de Marruecos creado con anterioridad -en 1941 (art. 2); entre las misiones a estos organismos (a estas "Juntas") encomendadas se encontraban la de la conservación de los monumentos, los edificios y los “objetos históricos y artísticos y antigüedades" (explicitados tal cual en el

Reglamento de 1955 de las Juntas Superior y Locales (Territoriales) de Monumentos del Protectorado, siendo referencias clave en estos artículos términos y conceptos como los de "catalogación”, "conservación", e ideas como la de la responsabilidad de la administración marroquí en la preservación de la "riqueza" (i.e., el Patrimonio) histórica, artística y arqueológica y en la conservación de la misma evitando su destrucción o enajenación.

29. Valderrama (1956: 792)

30. Reglamento dependiente del propio del Patronato de Alta Cultura si bien quizá no del todo casualmente emitido el mismo año que la Ley española de 1955, que reformaba la del "Tesoro Artístico" de 1933. art. 3.a), “...impidiendo su destrucción, traslado de lugar y venta con destino al extranjero...", punto que habla por sí mismo de la voluntad de preservación de la cultura material y de los bienes de la Cultura, a los que se sigue dotando de un marco legal de protección desde la autoridad marroquí y desde la administración conjunta del Protectorado, al tiempo que se les define como tales; el punto 3.b. del articulado del Reglamento de 1955 señala además como competencia y tarea de las Juntas Superior y Territoriales (supralocales, pero que en buena parte de los casos - como en los de Tetuán, Larache o Chauen- tenían igualmente la condición de Locales) la de catalogar el Patrimonio (entendido como "riqueza" nacional ${ }^{31}$ ) histórico, artístico y arqueológico así como la de conservar adecuadamente esta "riqueza" (inmueble y mueble), sin obviar las obligaciones en materia de investigación. De este modo, términos y conceptos como los de "catalogación", "reconocimiento", "conservación", o el de "trazado de planes generales de exploraciones y estudios" aparecen directamente recogidos y enunciados en el Reglamento de 1955, definiendo las líneas de actuación en materia de gestión del Patrimonio Cultural (nombrado como "Artístico e Histórico") de la administración de los que habrían de ser los últimos momentos del Protectorado.

Como puede comprobarse, existe un camino de continuidad desde el Dahir Vizirial de 1913 hasta el Reglamento de 1955, un camino que pasa por la reforma de 1919, y por otras disposiciones como las de 1920, 1921, 1938, 1953 (emitidas por la autoridad marroquí o en combinación con la autoridad española, caso de la Ordenanza del Patronato de Alta Cultura, dada por la autoridad española en 1941 y reformada por el Dahir de julio de 1953), combinadas con la acción de las normativas legales generales españolas como las leyes de 1911 y de 1933, con sus correspondientes desarrollos en 1912 y 1936, amén de disposiciones administrativas como la de 1927 o reglamentos como el de 1918 (relativo a las Comisiones Provinciales de Monumentos).

Por lo que respecta a la composición y organización de las mencionadas Juntas Territoriales, el Reglamento de 1955 define la existencia de cinco, sujetas a la jurisdicción de la Junta Superior; serían estas Juntas Territoriales las de la Yebala (que sería además la Junta Local de Tetuán), la Junta Territorial del Luccus (que actuaría como Junta Local de Larache), la Territorial de Gomara-Chauen (que funcionaría como Local de Chauen), la Junta Territorial del Rif (con sede en Villa

31. En la misma línea de concepto que lleva a hablar del "Tesoro Artístico Nacional”, tal y como aparecía en el título y el articulado de la Ley española de 1933. 
Sanjurjo) y la Junta Territorial del Quert (radicada en Nador), definiéndose en el articulado del Reglamento igualmente la composición de cada una de dichas Juntas Superior y Territoriales (arts. 4 a 9, ambos inclusive). Dato asimismo interesante será el aportado por el artículo 10 , donde se señala que uno de los miembros de la Junta Superior de Monumentos Artísticos e Históricos del Protectorado - designado por la propia Juntala representaría en el Patronato de Investigación y Alta Cultura de Marruecos, organismo en el que estaría, de este modo, representada la administración cultural del Protectorado español (o, lo que es lo mismo, el Norte de Marruecos). Las Juntas Locales y Territoriales estaban obligadas a dar cuenta a la Superior (mediante las correspondientes Memorias anuales) de su trabajo; con estas Memorias Locales, la Junta Superior elaboraría una Memoria General, que debía ser presentada, a su vez, al Patronato de Investigación y Alta Cultura de Marruecos para su consideración ${ }^{32}$.

Otro organismo a tener igualmente en cuenta en el marco del desarrollo y puesta en funcionamiento de este proceso de configuración de estructuras (dedicadas a la gestión del Patrimonio Cultural normarroquí) sería el Instituto General Franco (sic) para la Investigación Hispano-Árabe (del que hemos hecho mención supra y cuya sede principal se establecería no en Tetuán, sino en la cercana ciudad de Tánger) ${ }^{33}$, organismo éste que surge de modo contemporáneo a la creación de las instituciones anteriormente mencionadas (Pons 1998: 249 ss.; Díaz 2002: 143 ss.) y cuyas funciones se centran en el fomento de la investigación y la publicación de los resultados de la misma (en castellano y en árabe) ${ }^{34}$. Estos habrían de ser algunos de los elementos principales entre las diversas bases de carácter y naturaleza legal y administrativa (grosso modo) relativas a la gestión del Patrimonio Cultural (Arqueológico incluido) que vinieron a enmarcar el desenvolvimiento del trabajo cotidiano de cuidado y gestión del Patrimonio Histórico en el Norte de África, sin olvidar la legislación española relativa al conjunto total del territorio del Estado.

32. Valderrama (1956: 738 ss.).

33. Para la evolución de los organismos arabistas en España desde las Escuelas de Estudios Árabes de Madrid y Granada (que datan de 1932, y se configuran sobre un proyecto anterior, del año 1908), hasta el referido Instituto General Franco, que se transformaría en el Instituto Hispano-Árabe de Cultura, para desde esa identidad pasar a convertirse en el Instituto de Cooperación con el Mundo Árabe (configuración que adoptaría a fines de los ochenta del pasado siglo XX), cfr. Díaz (2002: 143 ss.); vemos de este modo cómo estas estructuras se han ido manteniendo a través de sus correspondientes transformaciones a lo largo del tiempo, desde un origen remoto en 1908 hasta el momento presente, 2009.

34. Cfr. Valderrama (1956: 814 ss.).
Como venimos contemplando, el embrión de la estructura administrativa de gestión del Patrimonio en el Norte de Marruecos germina inicialmente entre los años 1916 y 1919, con la creación de la Junta Superior de Estudios Históricos y Geográficos de Marruecos (1916) y de la Junta Superior de Monumentos Artísticos e Históricos (con sus respectivas delegaciones locales, en 1919), a cargo de la cual quedaron los trabajos de naturaleza arqueológica. Los primeros pasos de las campañas de excavación en los yacimientos arqueológicos de Tamuda (Tetuán) y de Lixus (Larache) habrían dado comienzo en 1921 y 1922, respectivamente.

En este mismo contexto de creación de estructuras y organismos de gestión (esto es, de configuración de una administración) se registrarían - desde el punto de vista organizativo- dos hechos referenciales para el ulterior desarrollo y continuidad de las actividades de naturaleza arqueológica en la región de Tetuán y coincidentes en tiempo y espacio; de una parte, la inspección girada por Manuel Gómez-Moreno (fruto de la cual sería su texto "Descubrimientos y antigüedades en Tetuán", aparecido originalmente en el Suplemento al Boletín Oficial de la Zona de Protectorado Español en Marruecos [noviembre de 1922]. Madrid, 1922, y que luego sería recogido igualmente en 1924, en la Revista Hispano-Africana) a los territorios en cuestión; de otra, la llegada al Norte de África y el inicio (ya mencionado) de los trabajos de César Luis de Montalbán y Mazas, directo responsable de las intervenciones arqueológicas realizadas desde la administración del territorio de la región septentrional de Marruecos durante los años 20 y 30 del siglo pasado ${ }^{35}$.

Respecto a los trabajos arqueológicos de campo desarrollados en la etapa de Montalbán ${ }^{36}$, es de señalar el predominio de las excavaciones por encima de otros posibles tipos de intervenciones (tales como prospecciones sistemáticas o asistemáticas, o labores de consolidación y restauración de monumentos y yacimientos). Montalbán, nombrado asesor técnico de la Junta Superior de Monumentos Artísticos e Históricos y con residencia en Larache, centraría sus esfuerzos -en lo que al trabajo arqueológico de campo se refiere- en yacimientos como los de Tamuda, Lixus, Tabernae, Ad-Mercuri y M'zora, aunque no sería posible hablar de un verdadero trabajo arqueológico sistemático (siquiera en estado embrionario) hasta 1926-1927 (tras la pacificación del territorio que seguiría al desembarco y posterior campaña militar de Alhucemas de 1925), coincidiendo con el ya mencionado R.D. de 23 de marzo de 1927 que determinó la

35. Cfr. Gozalbes Cravioto (2005: 329 ss.).

36. Vid. Valderrama (1956: 722 ss.). 
creación de la Junta de Investigaciones Científicas de Marruecos y Colonias. César Luis de Montalbán, primer arqueólogo español con responsabilidades directas en Marruecos (en lo relativo a la gestión del Patrimonio Histórico), excavó en Lixus (Larache) y Tamuda (Tetuán) desde su misma llegada al Magreb: algunas de las campañas iniciales de este arqueólogo pionero se fechan en $1921^{37}$ en Tamuda, junto a Tetuán, yacimiento que luego habría de ocupar los esfuerzos principales de Pelayo Quintero en lo que toca al trabajo de campo, y en el que igualmente intervendría activamente Miquel Tarradell Mateu (sucesor de Quintero en sus responsabilidades en 1948), y en el más occidental emplazamiento de la antigua ciudad de Lixus, junto al río Lukkus, igualmente a principios de la década de $1920^{38}$.

La gestión del Patrimonio Histórico-Arqueológico en la zona del Protectorado, sujeta a las normativas y organismos que hemos venido contemplando, se habría articulado de la siguiente manera: entre 1926 y 1936, el Servicio de Arqueología, radicado en Tetuán, habría estado bajo la competencia de la Junta Superior de Monumentos, siendo la persona responsable del mismo César Montalbán; tras el paréntesis de la guerra civil (1936-1939), entre 1939 y 1946, la ya Inspección General, sita igualmente en Tetuán pero dependiente de la Delegación de Cultura de la Alta Comisaría Española habría estado ocupada por Pelayo Quintero Atauri; al fallecimiento de Quintero se habría producido un período de "interinidad" de dos años y medio (19461948), momento en el que de manera provisoria las responsabilidades ejercidas por Pelayo Quintero habrían sido desempeñadas por dos de sus colaboradores (probablemente los más cercanos), Cecilio Jiménez (quien fuera secretario de Quintero y del Museo de Tetuán) y el sacerdote agustino César Morán Bardón (Gozalbes 2009); M. Tarradell habría finalmente de ocupar el

37. Señalaremos, a modo de referencia necesaria para una mejor comprensión global del momento y la situación en que se desarrollan estos trabajos de campo, que en 1921 se produjo el así llamado "Desastre de Annual", con la derrota de las tropas españolas del general Fernández Silvestre a manos de los rifeños de Abd El Krim, la muerte de varios miles de soldados españoles y el subsiguiente hundimiento de las líneas de defensa españolas en el territorio, todo lo cual habría de desembocar en el desembarco hispano-francés de Alhucemas de 1925 (y la consiguiente "pacificación" de los territorios); estas circunstancias bélicas (ciertamente extremas) "enmarcaban" el trabajo arqueológico desarrollado en el ámbito del Protectorado español en Marruecos.

38. Los trabajos que proporcionan una más inmediata y completa visión sobre Tamuda y la historia de los estudios sobre dicho yacimiento quizá sean los de M. Ghottes (2008) y J. Verdugo Santos (2008); sobre C. Montalbán, cfr. E. Gozalbes (2008); para Pelayo Quintero, cfr. Parodi (2008); en lo relativo a M. Tarradell, cfr. Blázquez (2006). puesto de Quintero en 1948, bajo las mismas circunstancias, el mismo esquema administrativo (i.e., Inspección General sujeta a la Delegación de Cultura de la Alta Comisaría Española), y responsabilidades.

Tras la inestabilidad del período anterior a 1927 y la relativa provisoriedad de las estructuras en las que se desarrollaron los trabajos de Montalbán, el panorama que encuentra Pelayo Quintero al llegar a Marruecos es el de unas estructuras en formación, que van contando con marcos legales y administrativos, pero que arrastran (no podía ser de otro modo) las penurias de la posguerra española y de la II Guerra Mundial. La tarea previa se ha repartido en varios yacimientos arqueológicos, en el reconocimiento y excavación de los mismos (como los de Lixus, Tamuda o M'zora, ya mencionados), en un esfuerzo fundamentalmente realizado desde la segunda mitad y los finales de los años 20 en adelante (esto es, en los 10-12 años anteriores al bienio 1939-40).

En el siglo XIX Marruecos, el Marruecos norteño, había atraído a viajeros e investigadores aún imbuidos de un cierto espíritu romántico (como el alemán Barth o los franceses Charles Tissot y Henri de la Martinière, que había centrado su interés en la zona de Lixus); la primera figura española con nombre propio en lo relativo a la materia arqueológica en aquellos territorios fue Teodoro de Cuevas, vicecónsul español en Larache a finales del XIX y cuyos trabajos son anteriores a los de Montalbán; otro personaje a considerar será el franciscano P. Lerchundi, establecido en la misión de su Orden en Tánger ${ }^{39}$. Será precisamente César Luis de Montalbán y Mazas quien (y ello pese a las condiciones en que se vio constreñido a trabajar) diera carta de organización a las labores arqueológicas en el Protectorado, perteneciendo ya sus trabajos a la sistemática de la administración, a las tareas regladas y organizadas dependientes no de iniciativas más o menos aisladas, sino a un trabajo inserto en unas estructuras administrativas que pudieran considerarse tales.

Este perfil (y esfuerzo) será plenamente desarrollado posteriormente por Pelayo Quintero Atauri. El de $\mathrm{Cuenca}^{40}$, tras una dilatada carrera profesional en la Península, será nombrado Inspector General de Excavaciones del Protectorado (con oficina radicada en Tetuán) ya en 1939, siendo esta Inspección por él dirigida la responsable de los trabajos de campo, y encontrándose

39. Una breve referencia sobre su respectivos roles en el territorio en Parodi (2009: 127, nn. 14-16).

40. Las poblaciones de Nohales y Uclés, en la provincia de Cuenca, se disputan su nacimiento, si bien se crió en esta última localidad, antigua cabecera de la Orden de Santiago. 
bajo la dependencia de la Delegación de Cultura de la Alta Comisaría de España en el Protectorado. Esta Inspección sería heredera del "Servicio de Arqueología" que desde mediados-fines de los años 20 y hasta ese momento ( 0 , más exactamente, hasta el inicio de la Guerra Civil española, en 1936) había venido desarrollando sus tareas en el Marruecos septentrional, Servicio radicado en Tetuán y encargado del estudio de las antigüedades preislámicas del territorio; habría dependido de la Junta Superior de Monumentos Históricos y Artísticos, estando a cargo de C.L. de Montalbán hasta la llegada de Quintero Atauri (Tarradell 1953-54: 8 ss.). Con la presencia de Quintero (algo que será más definitivamente sólido aún tras la llegada de Tarradell) puede hablarse de la definitiva consolidación de las estructuras de gestión de la administración española del Protectorado en materia Arqueológica; se habrá pasado de unas estructuras larvarias y débiles, a una organización cuando menos sólidamente inserta en el esquema administrativo de la Alta Comisaría, consolidada como tal y, aunque carente de medios materiales acordes con el volumen y la envergadura de la labor a desarrollar, plenamente consciente de sus responsabilidades como administración ${ }^{41}$.

La tarea arqueológica (el trabajo de campo) de Quintero -frente a lo acometido por Montalbán- se centrará casi con exclusividad en el tetuaní yacimiento de Tamuda, quizá por la proximidad al núcleo tetuaní de este sitio arqueológico (antigua ciudad mauritana-prerromana y romana, sita a los márgenes del río Martil, por aquellos entonces a cinco Km. de Tetuán, aunque hoy los arrabales de la ciudad se han aproximado bastante al sitio), habida cuenta además del estado de salud del de Cuenca. En las varias campañas arqueológicas que, de forma sucesiva y anual (a razón de una por año), se emprendieron bajo la directa dirección de P. Quintero (con quien en distintos momentos colaboraran (como se ha señalado) tanto el agustino C. Morán como el secretario del museo, C. Jiménez) en Tamuda (entre 1940 y 1945), se amplió la zona prospectada y excavada anteriormente en el referido yacimiento, poniéndose de relieve la importancia del mismo, y aumentando (como fruto y resultado de los trabajos de dichas campañas) el volumen de los fondos materiales depositados en el Museo Arqueológico tetuaní. Las relaciones ya existentes entre los territorios andaluz y tingitano en materia arqueológica (de las que teníamos constancia gracias a algún ejemplo de los años veinte), habrían continuado en estos momentos, de lo cual dejan constancia con sus

41. Algo que se debería en buena medida al sello personal del propio Quintero y de su superior, García Figueras. propias palabras, por ejemplo, la directora del Museo de Granada, Joaquina Eguarás Ibáñez (en la "Memoria" de dicho Museo del año 1945), quien habría visitado el Museo de Tetuán en varias oportunidades (por razones de estudio) contando siempre con el mejor recibimiento y trato por parte de Quintero (cfr. Eguarás 1946: 68 ss.), o la directora del Museo Arqueológico de Cádiz, C. Blanco Mínguez.

La definitiva consolidación de las estructuras de gestión del Patrimonio Histórico y Arqueológico del Norte de Marruecos (botón de muestra de lo cual podría ser la celebración del Congreso de 1953 , vendría a producirse, con la consolidación de organismos tales como el Patronato de Alta Cultura, las Juntas Superior y Territoriales de Monumentos y sus organismos dependientes (como las Inspecciones de Arqueología y de Bellas Artes), entre 1941 y 1953/55, justo en el momento en que la existencia del "envoltorio" que las cubría, el propio Protectorado, estaba tocando a su fin. Así, a partir de 1956 (y hasta 1959), esto es, el año inmediatamente después de la emisión del Reglamento de las Juntas de Monumentos (que data de 1955), sería desmantelada la presencia española en el septentrión magrebí, y con ella, se daría paso al fin de los órganos de gestión adscritos a dicha administración. Sería ya el Reino de Marruecos quien instituyera sus propios organismos destinados a tales fines.

\section{BIBLIOGRAFÍA}

ALEGRE ÁVILA, J.M. (1994): Evolución y régimen jurídico del Patrimonio Histórico. Análisis y Documentos, Ministerio de Cultura. Madrid.

BELÉN DEAMÓS, Ma . y BELTRÁN FORTES, J. (eds.) (2002): Arqueología fin de siglo. La Arqueología española de la segunda mitad del siglo XIX (I Reunión Andaluza de Historiografía Arqueológica). Spal Monografias III. Sevilla.

BELTRÁN FORTES, J. (2008): "En la otra orilla. La Arqueología española frontera a la del norte de Marruecos: algunas notas", en D. Bernal, B. Raissouni, J. Ramos, M. Zouak y M. Parodi (eds.), En la Orilla africana del Círculo del Estrecho. Historiografia y proyectos actuales. Colección de Monografías del Museo Arqueológico de Tetuán (II). Actas del II Seminario Hispano-Marroquí de Especialización en Arqueología: 185-203. Cádiz.

BELTRÁN FORTES, J. y GASCÓ LACALLE, F. (eds.) (1993): La Antigüedad como Argumento. Historiografía de arqueología e historia antigua en Andalucía. Sevilla. 
BERNAL, D.; EL KHAYARI, A.; RAISSOUNI, B.; ESSADRA, L.; DÍAZ, J.J.; SÁEZ, A.; BUSTAMANTE, M.; VILLADA, F.; LAGÓSTENA, J.; DOMÍNGUEZ, J.C.; PARODI, M. (2008): “El valle del río Martil en época preislámica e islámica. Primeros resultados de la Carta Arqueológica (Campaña 2008)", en D. Bernal, B. Raissouni, J. Ramos, M. Zouak y M. Parodi (eds.), En la Orilla africana del Círculo del Estrecho. Historiografia y proyectos actuales. Colección de Monografías del Museo Arqueológico de Tetuán (II). Actas del II Seminario Hispano-Marroquí de Especialización en Arqueología: 313-350. Cádiz.

BLANCO MíNGUEZ, C. (1943): "Museo Arqueológico de Cádiz", en Memorias de los Museos Arqueológicos Provinciales (en adelante MMAP) III. 1942: 104-107. Madrid.

- (1944): "Museo Arqueológico de Cádiz", en MMAP IV. 1943: 74-78. Madrid.

BLÁZQUEZ MARTÍNEZ, J.M․ (2000): “Tres grandes arqueólogos de Mauretania Tingitana: M. Ponsich, R. Thouvenot y M. Tarradell", en Atti del XIII Convegno Internazionale su l'Africa Romana (Djerba, Túnez 1998): 1089-1105. Roma.

- (2006): "La obra de Ponsich y Tarradell sobre Marruecos", en D. Bernal, B. Raissouni, J. Ramos y A. Bouzzouggar (eds.), Actas del I Seminario Hispano-Marroquí de Especialización en Arqueología: 47-53. Cádiz.

CANTERO, J. y VERDUGO, J. (redactores) (2008): "El Plan Estratégico de la Zona Patrimonial de $T a$ muda (PET)", en D. Bernal, B. Raissouni, J. Ramos, M. Zouak y M. Parodi (eds.), En la Orilla africana del Círculo del Estrecho. Historiografía y proyectos actuales. Colección de Monografias del Museo Arqueológico de Tetuán (II). Actas del II Seminario Hispano-Marroqui de Especialización en Arqueología: 627-679. Cádiz.

DÍAZ-ANDREU, M. (2002): Historia de la Arqueología. Estudios. Madrid.

DÍAZ-ANDREU, M.; MORA RODRÍGUEZ, G. y CORTADELLA MORRAL, J. (coords.) (2009): Diccionario Histórico de la Arqueología en España (siglos $X V-X X$ ). Marcial Pons, Madrid.

EGUARÁS IBÁÑEZ, J. (1946): "Museo Arqueológico de Granada", en MMAP VI. 1945: 68-72. Madrid.

ESPASA-CALPE (1922): T.XLVIII, voz "Quintero de Atauri (Pelayo)", pp. 1391-1392.

GARCÍA DE ENTERRÍA, E. (1983): “Consideraciones sobre una nueva legislación del patrimonio histórico y cultural", en REDA 39. Madrid.

GASCÓ LACALLE, F. y BELTRÁN FORTES, J. (eds.) (1995): La Antigüedad como Argumento II.
Historiografía de arqueología e historia antigua en Andalucía. Sevilla.

GHOTTES, M. (1991): Tamuda. Tánger.

- (2008): "Histoire des fouilles à Tamuda", en D. Bernal, B. Raissouni, J. Ramos, M. Zouak y M. Parodi (eds.), En la Orilla africana del Círculo del Estrecho. Historiografía y proyectos actuales. Colección de Monografías del Museo Arqueológico de Tetuán (II). Actas del II Seminario Hispano-Marroqui de Especialización en Arqueología: 459-472. Cádiz.

GHOTTES, M. y PARODI ÁLVAREZ, M.J. (e.p.): "Le fleuve Tamuda”, en M.J. Parodi Álvarez (coord.), Pelayo Quintero Atauri, 1867-1946.

GOZALBES CRAVIOTO, E. (1982): Atlas Arqueológico del Marruecos Mediterráneo. Granada.

- (2003): "África Antigua en la historiografía y arqueología de época franquista", en F. Wulff y M. Álvarez (eds.), Antigüedad y franquismo (19361975): 135-160. Málaga.

- (2005): "Las excavaciones arqueológicas de 19211922 en Tamuda (Tetuán, Marruecos)", en Cuadernos del Archivo Central de Ceuta 14: 325-342.

- (2005b): "Los inicios de la investigación española sobre Arqueología y Arte árabes en Marruecos (1860-1960)", Boletín de la Asociación española de Orientalistas, año XLI: 225-246.

- (2006): "El monumento protohistórico de Mezora (Arcila, Marruecos)", Archivo de Prehistoria Levantina XXVI: 323-348.

- (2007): "Algunos avatares de la Arqueología colonial en el Norte de Marruecos (1939-1942)", Boletín de la Asociación Española de Orientalistas, año XLIII: 77-96.

- (2008): "Los primeros pasos de la Arqueología en el norte de Marruecos", en D. Bernal, B. Raissouni, J. Ramos, M. Zouak y M. Parodi (eds.), En la Orilla africana del Círculo del Estrecho. Historiografía y proyectos actuales. Colección de Monografías del Museo Arqueológico de Tetuán (II). Actas del II Seminario Hispano-Marroqui de Especialización en Arqueología: 33-61. Cádiz.

- (2009): "El padre César Morán Bardón. La Arqueología y la Etnografía, de Salamanca a Marruecos", en Salamanca. Revista de Estudios 57: 51-63.

JIMÉNEZ, C. (1947): “Excmo. Sr. D. Pelayo Quintero", en MMAP VII. 1946: 7-8. Madrid.

KBIRI ALAOUI, M. (2006): "Marruecos púnico: historia y desarrollo de la investigación académica", en D. Bernal, B. Raissouni, J. Ramos y A. Bouzzouggar (eds.), Actas del I Seminario Hispano-Marroquí de Especialización en Arqueología: 145155. Cádiz. 
LAMOURI, M. (2007): “L'Internalisation de la question marocaine: 1880-1912”, en J.M. de Faramiñán Gilbert y V.L. Gutiérrez Castillo, La Conferencia de Algeciras y las relaciones internacionales: $207-$ 220. Fundación Tres Culturas. Sevilla.

LÓPEZ TRUJILLO, M.A. (2004): "Las Comisiones Provinciales de Monumentos, Quijotes del pasado", en Pioneros de la Arqueología en España del siglo XVI a 1912. Zona Arqueológica 3: 363-369. Alcalá de Henares.

MAIER ALLENDE, J. (2004): "La Real Academia de la Historia y la Arqueología Española en el siglo XIX”, ERES 12 (febrero): 91-121.

MAIER, J. y SALAS, J. (2000): Comisión de Antigüedades de la Real Academia de la Historia. Andalucía. Catálogo e Índices. Madrid.

MARTÍNEZ DE NAVASCUÉS, J.M. (1944): “Memoria-Resumen de la Inspección General", en $M M A P$ IV. 1943: 17-18. Madrid.

NEIRA JIMENEZ, M.L. (2000): "Las expediciones de la primera mitad del siglo XIX al Norte de Africa. Su contribución al descubrimiento y estudio de los mosaicos romanos", en Atti del XIII Convegno Internazionale su l'Africa Romana (Djerba, Túnez 1998): 797-816. Roma.

PARODI ÁlVAREZ, M.J. (2006): “La Razón de la Sinrazón. Cayo César, el obelisco y las lentejas", en G. Chic García (dir.), Economía de prestigio versus Economía de mercado: 89-101. Sevilla.

- (2007): “Arqueología española en Marruecos, 19391946. Pelayo Quintero de Atauri”, Spal 15 (2006): 9-20. http://dx.doi.org/10.12795/spal.2006.i15.01

- (2008): "Notas sobre Historiografía Arqueológica Hispano-Marroquí. 1939-1946, Pelayo Quintero", en D. Bernal, B. Raissouni, J. Ramos, M. Zouak y M. Parodi (eds.), En la Orilla africana del Círculo del Estrecho. Historiografía y proyectos actuales. Colección de Monografías del Museo Arqueológico de Tetuán (II). Actas del II Seminario Hispano-Marroqui de Especialización en Arqueología: 63-92. Cádiz.

- (2008b): "Pelayo Quintero de Atauri. Apuntes de Arqueología hispano-marroquí, 1939-1946”, en J. Beltrán y M. Habibi (eds.), Historia de la Arqueología en el Norte de Marruecos durante el Protectorado y sus referentes en España: 97-119. Universidad Internacional de Andalucía y Universidad de Sevilla. Sevilla.

- (2008c): "Pelayo Quintero: Arqueología en las dos orillas del Fretum Gaditanum", en Actas del XVII Convegno dell'Africa Romana. Sevilla, diciembre 2006: 2517-2526. Roma.
- (2009): "Notas sobre la organización administrativa de las estructuras de gestión del Patrimonio Arqueológico en el Marruecos Septentrional durante el Protectorado (1912-1956)", Heraklion (rev. digital) 2: 117-141.

- (e.p.): "Pelayo Quintero: Arqueología en las dos orillas del Fretum Gaditanum", en "XVII Convegno dell'Africa Romana”. Sevilla, diciembre 2006 (Actas en prensa).

- (e.p.): "Entre Cádiz y Tetuán en la primera mitad del siglo XX. Quintero Atauri", en las III Jornadas de Cooperación Cultural Hispano-Marroquí. Estudios Historiográficos hispano-marroquies en el Norte de Marruecos: estado de la cuestión. Fundación Provincial de Cultura de la Diputación de Cádiz, Universidad Abdelmalek Essaâdi de TetuánTánger. Tetuán.

- (e.p.): "Los años definitivos. Marruecos, 19391946”, en M.J. Parodi Álvarez (coord.), Pelayo Quintero Atauri. Actas de las Jornadas sobre "Pelayo Quintero en el Primer Centenario de La Pepa", celebradas en Cádiz los días 6 y 7 de noviembre de 2007. Diputación de Cádiz - Junta de Andalucía. PARODI ÁlVAREZ, M.J. y PARODI ÁlVAREZ, S. (2001): "Coerción y control de la Educación durante la Guerra Civil: el caso de Puerto Real (Cádiz)", en Espacio y Tiempo 15: 213-227. Sevilla.

PONS PUJOL, L (1998): "Notas de Historiografía española sobre arqueología marroquí", Pyrenae 29: 249-255.

RAISSOUNI, B. (2006): "Nouvelles perspectives de recherches archéologiques au Nord du Maroc", en D. Bernal, B. Raissouni, J. Ramos y A. Bouzzouggar (eds.), Actas del I Seminario Hispano-Marroqui de Especialización en Arqueología: 229-232. Cádiz.

REMACHA TEJADA, J.R. (2007): “El Estatuto Internacional del Protectorado Español en Marruecos tras la Conferencia de Algeciras (1912-1956)", en A. del Valle Gálvez y J. Verdú Baeza (dirs.), España y Marruecos en el Centenario de la Conferencia de Algeciras: 67-80. Madrid.

ROUSSEAU, CH. (1966): Derecho Internacional público. Ed. Ariel, Barcelona.

SAN NICOLAS PEDRAZ, M.P. (2000): "Historiografía de la musivaria romana de Mauretania Tingitana", en Atti del XIII Convegno Internazionale su l'Africa Romana (Djerba, Túnez 1998): 1073-1087. Roma.

TARRADELL MATEU, M. (1953-1954): "Las actividades arqueológicas en el Protectorado español de Marruecos", separata del IV Congreso Internacional 
de Ciencias Prehistóricas y Protohistóricas. Zaragoza-Madrid (37 pp. 5 ill.).

VALDERRAMA MARTÍNEZ, F. (1956): Historia de la acción cultural de España en Marruecos (19121956). Tetuán.

VALLE PANTOJO, A.F. del (2007): "El papel de Italia en la Conferencia Internacional de Algeciras de 1906”, en J.M. de Faramiñán Gilbert y V.L. Gutiérrez Castillo, La Conferencia de Algeciras y las relaciones internacionales: 325-346. Fundación Tres Culturas, Sevilla.

VERDÚ BAEZA, J. y TORREJÓN GÓMEZ, J.D. (2007): "La Conferencia de Algeciras de 1906: significado y contexto histórico", en A. del Valle Gálvez y J. Verdú Baeza (dirs.), España y Marruecos en el Centenario de la Conferencia de Algeciras: 44-65.

VERDUGO SANTOS, J. (2005-2006): "Plan Estratégico de Tamuda: una experiencia de cooperación al desarrollo en el ámbito de la economía de la Cultura", Cuadernos de Economía de la Cultura 4-5: 179-186. Sevilla.

VERDUGO SANTOS, J. y JIMÉNEZ BARRIENTOS, J.C. (2007): "El Plan Estratégico de Tamuda: un instrumento para la puesta en valor y musealización de un sitio arqueológico en el marco de la cooperación internacional", en Actas del IV Congreso Internacional sobre musealización de Xacementos Arqueológicos Vol. V, Proxectos e experiencias: 197-204. Santiago de Compostela.

VILLAFRANCA JIMÉNEZ, Ma . del M. (1998): "Los museos andaluces: pasado, presente y perspectivas de futuro", en Revista de Mueseología $n^{\circ} 13$, febrero. A.E.M., Madrid.

ZOUAK, M. (2006): “El Museo Arqueológico de Tetuán. Las civilizaciones de la otra orilla del Mediterráneo", en Actas del I Seminario Hispano-Marroquí de especialización en Arqueología: 343-346. UCA, Cádiz.

- (2008): "El Arqueológico de Tetuán, una plataforma científica para el conocimiento de las civilizaciones humanas del Estrecho de Gibraltar", en D. Bernal, B. Raissouni, J. Ramos, M. Zouak, M. Parodi (eds.), En la Orilla africana del Círculo del Estrecho. Historiografia y proyectos actuales. Colección de Monografias del Museo Arqueológico de Tetuán (II). Actas del II Seminario Hispano-Marroquí de Especialización en Arqueología: 221-229. Cádiz.

ZOUAK, M. y PARODI ÁlVAREZ, M.J. (e.p.): "Pelayo Quintero y el Arqueológico de Tetuán”, en M.J. Parodi Álvarez (coord.), Pelayo Quintero Atauri, 1867-1946. 